\title{
Sex differences and sex hormone effects in long-QT syndrome: what can we learn from rabbit models?
}

\author{
Katja E. Odening • Manfred Zehender • \\ Christoph Bode $\cdot$ Michael Brunner
}

Published online: 19 February 2013

(C) Springer-Verlag Berlin Heidelberg 2013

\begin{abstract}
Patients with inherited long-QT syndrome (LQTS) exhibit pronounced sex differences in cardiac repolarization and in the incidence of arrhythmias: Adult women have longer QT intervals and a higher risk to develop potentially lethal torsade-de-pointes (TdP) ventricular tachycardia and sudden cardiac death (SCD) than men. Rabbit models exhibit similar sex differences with longer QT intervals and a higher propensity to additional drug-induced QT prolongation and drug-induced TdP in females. Since rabbits also have similar cardiac repolarizing currents as human subjects, they provide a useful system to explore sex differences in cardiac repolarization and arrhythmogenesis in LQTS and to reveal the underlying molecular mechanisms. This review article summarizes clinical observations on sex differences and sex hormone effects on cardiac repolarization and arrhythmogenesis in patients with LQTS and recapitulates findings on underlying mechanisms (sex hormone effects on ion channels and $\mathrm{Ca}^{2+}$-cycling proteins) and their clinical implications in drug-induced and transgenic rabbit models of LQTS.
\end{abstract}

Keywords Long-QT syndrome - Sex hormones · Sudden cardiac death $\cdot$ Ion channels $\cdot$ Rabbit models

PD Dr. med. K. E. Odening, MD $(\varangle)$ •

Prof. Dr. med. M. Zehender, MD · Prof. Dr. med. C. Bode, MD .

Prof. Dr. med. M. Brunner, MD

Department of Cardiology and Angiology I, Heart Center

Freiburg University, Hugstetter Str. 55, 79106 Freiburg, Germany

e-mail: katja.odening@universitaets-herzzentrum.de

M. Brunner, MD

Karl Landsteiner Institute for Cardiovascular Research,

Hospital Hietzing, Vienna, Austria
Zusammenfassung Long-QT Syndrom (LQTS) Patienten zeigen ausgeprägte Geschlechtsunterschiede in der Dauer ihrer kardialen Repolarisationsphase und ihres Arrhythmierisikos. So haben erwachsene LQTS-Patientinnen nicht nur längere QT Intervalle im Oberflächen-EKG, sondern sind auch einem höheren Risiko für das Entstehen von ventrikulären torsade-de-pointes Tachykardien (TdP) und dem daraus resultierenden plötzlichen Herztod ausgesetzt als Männer. Kaninchen zeigen ähnliche Geschlechtsunterschiede: Weibliche Kaninchen haben längere QT Intervalle, ein höheres Risiko für zusätzliche, medikamenten-induzierte QT-Verlängerungen und insbesondere eine höhere Inzidenz medikamenten-induzierter TdP-Arrhythmien als männliche Kaninchen. Da in Kaninchen zudem die gleichen repolarisierenden Ionenströme für die kardiale Repolarization verantwortlich sind wie beim Menschen, eignen sich Kaninchenmodelle sehr gut, um Geschlechtsunterschiede in der kardialen Repolarizationsphase und bei long-QT-assoziierten Arrhythmien näher zu untersuchen und die zugrunde liegenden molekularen Mechanismen aufzudecken. Dieser Review-Artikel fasst 1. klinische Beobachtungen zu Geschlechtsunterschieden und Geschlechtshormon-Effekten auf die kardiale Repolarization und das arrhythmogene Risiko bei LQTS Patienten zusammen und stellt 2. Forschungsergebnisse zu den zugrunde liegenden Mechanismen (Hormon-Wirkungen auf Ionenkanäle und CalciumTransport-proteine) in medikamenten-induzierten und transgenen LQTS Kaninchenmodellen vor.

Schlüsselwörter Long-QT Syndrom •

Geschlechtshormone · Plötzlicher Herztod ·

Kardiale Ionenkanäle $\cdot$ (transgene) Kaninchenmodelle 


\section{Introduction}

The incidences of several ventricular and supraventricular types of arrhythmias - such as long-QT-related arrhythmias and paroxysmal supraventricular tachycardias - differ with gender and particularly, vary pronouncedly with different menstrual phases, pregnancy, and the postpartum phase [1-5]. These clinical observations strongly suggest that sex hormones can have an impact on arrhythmogenesis.

Since functionally active androgen, estradiol, and progesterone receptors are present in atrial and ventricular cardiomyocytes [6-9], sex hormones may influence arrhythmogenesis via sex hormone receptor-mediated genomic modulation of the expression of cardiac ion channels and calcium-handling proteins. Moreover, sex hormones can acutely alter electrical properties of ion currents via nongenomic pathways involving nitric oxide [10]. Sex hormones may also affect arrhythmogenesis indirectly, e.g., by their effects on basal body temperature [11] and on sympathetic activity [12] that can both alter electrophysiological properties of several cardiac ion currents such as sodium, calcium, and potassium currents [12-14].

Rabbits have similar cardiac repolarizing currents as humans $[15,16]$ and exhibit similar sex differences in cardiac repolarization and long-QT-related arrhythmias $[17,18]$, making the rabbit a useful model system to explore sex differences in cardiac repolarization and arrhythmogenesis and their underlying molecular mechanisms.

This article focuses on the arrhythmogenic disease longQT syndrome (LQTS), and summarizes sex differences and sex hormone effects on cardiac repolarization and arrhythmogenesis in patients with LQTS. Moreover, it recapitulates findings on underlying mechanisms and their clinical implications in drug-induced and transgenic rabbit models of LQTS.

\section{Clinical observations: sex differences and sex hormone effects in long-QT syndrome}

The inherited LQTS is a heterogeneous arrhythmogenic disease, in which an impaired cardiac repolarization predisposes patients to torsade-de-pointes (TdP) tachycardia, syncopes, and sudden cardiac death (SCD) [19]. Data from the international LQTS registry demonstrate pronounced sex differences in cardiac repolarization and the incidence of arrhythmias: adult women with LQT type 1 (mutation in $\mathrm{KvLQT} 1 / \mathrm{I}_{\mathrm{Ks}}$ ) and type 2 (mutation in $\mathrm{HERG} / \mathrm{I}_{\mathrm{Kr}}$ ) have longer QT intervals and a higher risk for TdP and SCD than men [20-22]. Moreover, during adulthood, female gender is a major independent risk factor for SCD independent of genotype or the location of the mutation within the gene [21-23].
In contrast, before puberty, the incidence of arrhythmias is higher in boys than in girls [24].

Several observations suggest that sex hormones confer these sex differences: different phases of menstrual cycle, pregnancy, and postpartum period are associated with changes in QT duration and incidence of TdP. In acquired LQTS, drug-induced QT prolongations and the arrhythmogenic risk are more pronounced during menses and follicular phase (with high estradiol levels) than during luteal phase (with relatively higher progesterone levels) [1]. Pregnant LQT2 patients have a reduced arrhythmogenic risk, while the risk markedly increases during the 9-month postpartum period [2]. These observations strongly suggest a proarrhythmic effect of estradiol and an antiarrhythmic effect of progesterone in LQTS.

\section{LQTS rabbit models: insights into sex differences and sex hormone effects on cardiac repolarization and arrhythmogenesis}

Rabbits exhibit similar sex differences as human subjects: female rabbits have longer QT intervals [17], a more pronounced drug-induced QT prolongation, and a higher incidence of drug-induced TdP than males [18] (Table 1). Since rabbits also have similar repolarizing currents as humans $[15,16]$, they provide a useful system to explore these sex differences in cardiac repolarization and arrhythmogenesis and to reveal the underlying molecular mechanisms.

Castration and subsequent exposure to sex hormones revealed hormone-effects on cardiac repolarization and arrhythmogenesis. Pham et al. [25] found similar action potential duration (APD) in castrated male and female rabbits. Moreover, castration reverses the normal sex differences in drug-sensitivity: orchiectomy prolongs APD and increases the incidence of $\mathrm{I}_{\mathrm{Kr}}$-blocker induced early afterdepolarizations (EAD), while ovariectomy reduces drug-induced APD prolongation and EADs [25] (Table 1).

The normal female phenotype with an increased risk for drug-induced TdP can be mimicked by treating ovariectomized or orchiectomized rabbits with estradiol $[18,25,26]$, while a combined treatment with estradiol and progesterone reduces the risk for drug-induced arrhythmias [27]. Exposing castrated rabbits to testosterone shortens QT duration and reduces drug-induced QT prolongation and EADs $[18,28]$, suggesting that sex hormones - and not only the genetic sex-account for sex differences in cardiac repolarization.

Using a transgenic LQT2 rabbit model that mimics the human LQT2 phenotype [29,30], we investigated the role of sex hormones in cardiac repolarization and arrhythmogenesis in vivo. We demonstrated that estradiol steepens QT/RR ratio by prolonging QT duration, particularly at slow heart 


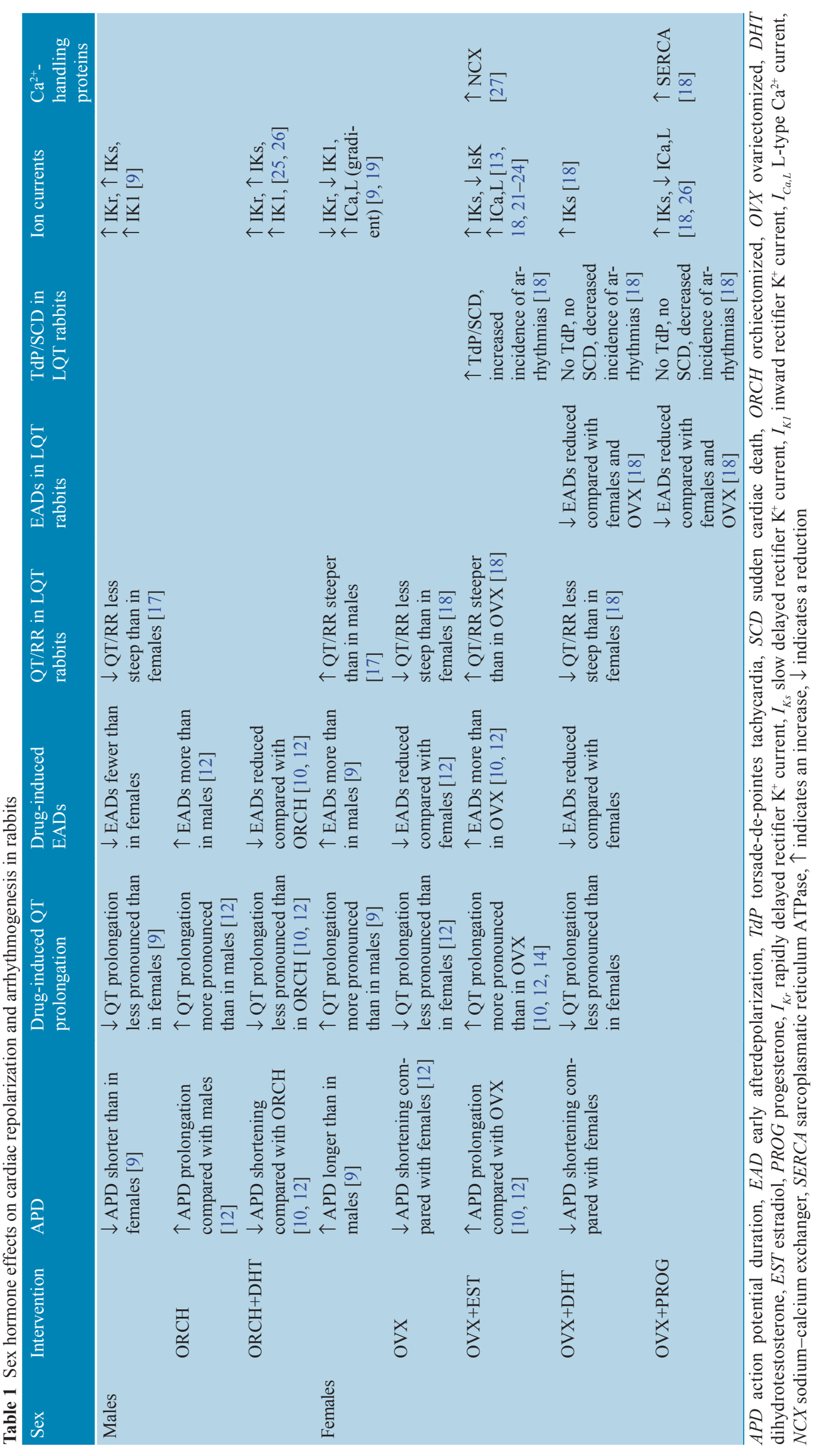


rates, while testosterone decreases QT/RR slope steepness [31], similarly as observed in human LQT2 patients. Moreover, we could demonstrate a proarrhythmic effect of estradiol and an antiarrhythmic, protective effect of progesterone, which completely abolishes the occurrence of TdP or SCD. On the organ level, we identified a reduced rate of EADs in response to sympathetic stimulation as underlying mechanism of this protective progesterone effect [31] (Table 1).

\section{Cellular studies: sex hormone effects on ion currents and $\mathrm{Ca}^{2+}$-cycling proteins}

Current densities of rapid delayed rectifier current $\mathrm{I}_{\mathrm{Kr}}$ and inward rectifier current $\mathrm{I}_{\mathrm{K} 1}$ are lower in female than in male rabbits' ventricular cardiomyocytes [17]. This lower $\mathrm{I}_{\mathrm{Kr}}$ is thought to account for the higher sensitivity of females to $\mathrm{I}_{\mathrm{Kr}}$-blocking drugs [17]. Moreover, female but not male rabbits exhibit a transmural gradient of $\mathrm{I}_{\mathrm{Ca}, \mathrm{L}}$ with a higher epi- than endocardial $\mathrm{I}_{\mathrm{Ca}, \mathrm{L}}[32]$. Ovariectomy eliminates this transmural gradient, which reappears upon estradiol treatment. In contrast, orchiectomized rabbits have no transmural gradient of $\mathrm{I}_{\mathrm{C}, \mathrm{L}}$ even after exposure to estradiol, suggesting a potential genetic difference in the mechanism of action of sex hormones (Table 1).
Recently, these findings on sex differences in cardiac ion channels have been corroborated in human cardiac tissue derived from nondiseased transplant donors. Using a highthroughput approach, Gaborit et al. [33] could demonstrate a reduced expression of several repolarizing $\mathrm{K}^{+}$-channel subunits such as HERG, KCNE1, and Kir2.3 in female hearts.

To increase our understanding of these sex differences, sex hormone effects on cardiac ion currents/channel proteins have been investigated. Estradiol downregulates KCNE1 ( $\beta$-subunit to KvLQT1 to form $\mathrm{I}_{\mathrm{Ks}}$ ) [26], directly inhibits $\mathrm{I}_{\mathrm{Kr}}[34,35]$, and indirectly reduces $\mathrm{I}_{\mathrm{Kr}}$ by upregulating the $\beta$-subunit KCNE2 [36]. Moreover, estradiol increases $I_{C a, L}$ [31] and accentuates the base-to-apex gradient of $\mathrm{I}_{\mathrm{Ca}, \mathrm{L}}$ in rabbits [37] (Fig. 1). All these effects result in an APD and QT prolongation and an increased dispersion of repolarization. Moreover, a synergistic effect of estradiol and $\mathrm{I}_{\mathrm{Kr}}$-blocking drugs on $\mathrm{I}_{\mathrm{Kr}}$ currents was recently reported [35]. In contrast, testosterone increases $\mathrm{I}_{\mathrm{Kr}}$ and $\mathrm{I}_{\mathrm{K} 1}$ in rabbits' cardiomyocytes [38], and increases $\mathrm{I}_{\mathrm{Ks}}$ and decreases $\mathrm{I}_{\mathrm{Ca}, \mathrm{L}}$ in guinea pigs' cardiomyocytes [39], thus shortening APD and QT duration. Progesterone also shortens APD by decreasing $\mathrm{I}_{\mathrm{Ca}, \mathrm{L}}$ and increasing $\mathrm{I}_{\mathrm{Ks}}[31,39]$ (Table 1, Fig. 1).

In addition, sex hormone effects on expression and function of $\mathrm{Ca}^{2+}$-cycling proteins have been investigated. Estradiol increases the expression and function of sodium-

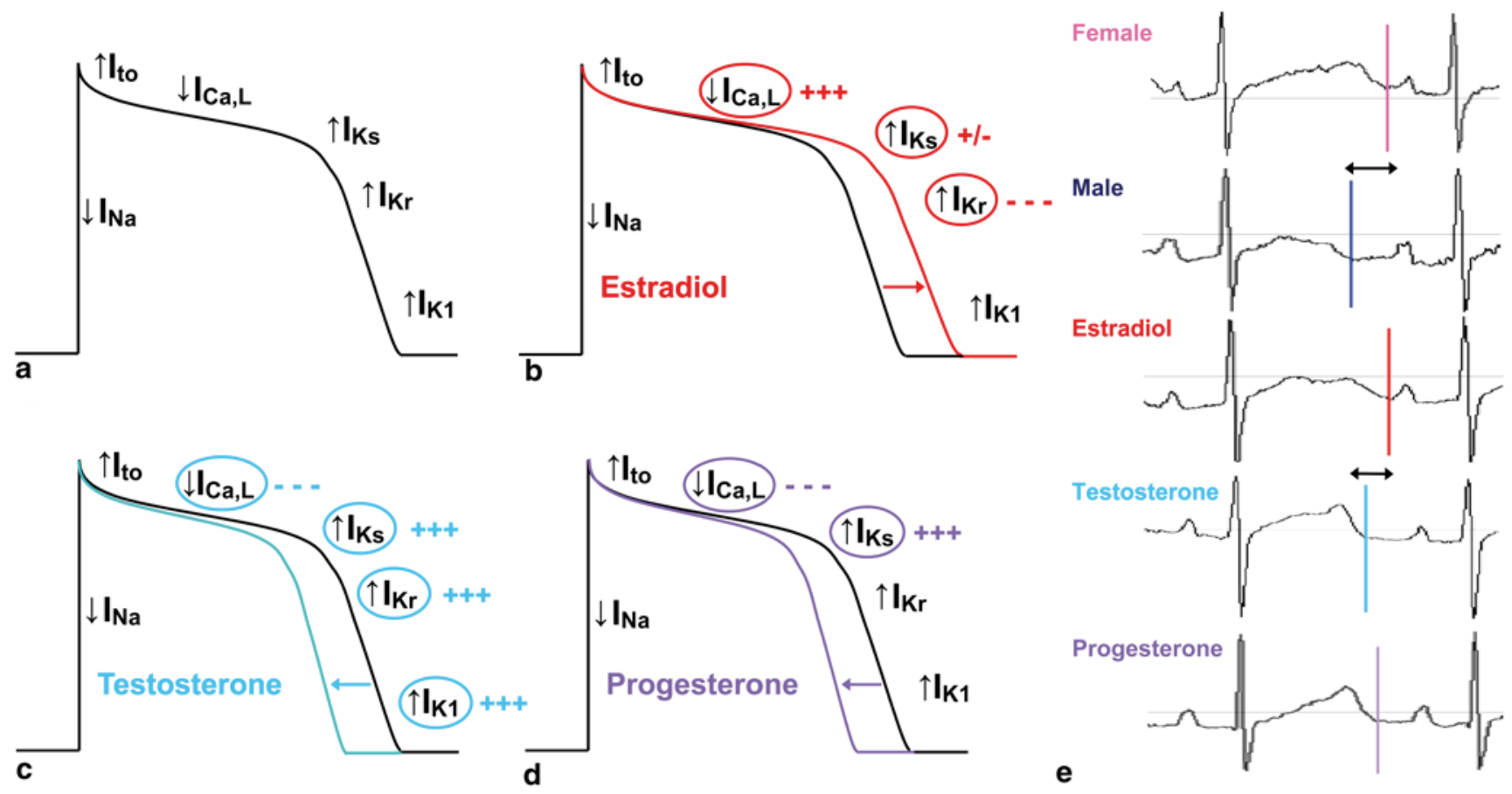

Fig. 1 (a) Schematic figure of cardiac action potential and depolarizing and repolarizing ion currents. $\uparrow$ Arrows indicate outward currents, $\downarrow$ arrows indicate inward currents. $I_{N a}$ Depolarizing $\mathrm{Na}^{+}$current, $I_{t o}$ transient outward $\mathrm{K}^{+}$current, $I_{C a, L}$ L-type $\mathrm{Ca}^{2+}$ current, $I_{K r}$ rapidly delayed rectifier $\mathrm{K}^{+}$current, $I_{K s}$ slowly delayed rectifier $\mathrm{K}^{+}$current, $I_{K I}$ inward rectifier $\mathrm{K}^{+}$current. (b-d) Schematic figure of estradiol's (b), testosterone's (c), and progesterone's (d) effects on cardiac ion currents and on action potential duration. +++ Increase, --- decrease, +/- differential effects on alpha- and beta-subunits. e Sex differences and sex hormone effects on QT duration in transgenic LQT2 rabbits. (e) Modified and adapted from [31] 
calcium exchanger NCX [40] that may contribute to an increased EAD formation in female rabbits. We reported a progesterone-induced increased SERCA2a expression in transgenic LQT2 rabbits, which may contribute to the antiarrhythmic effect of progesterone by shortening $\mathrm{Ca}^{2+}$ transient duration [39].

\section{Clinical implications}

As women with LQT1 and LQT2 have a higher risk for TdP and SCD than men and are particularly prone to develop lethal TdP during the postpartum [20,22], a particularly close clinical monitoring of female LQT patients is mandatory, especially in phases of changing hormone levels. Understanding the exact mechanisms that underlie sex hormone effects on cardiac repolarization and arrhythmogenesis in inherited LQTS will help to better discern the individual risk of LQT patients. Moreover, as studies in transgenic LQT2 rabbits indicate an antiarrhythmic, protective effect of progesterone [31], clinical studies investigating new hormone-based therapeutic options in LQTS are clearly warranted.

Acknowledgments This article is part of a supplement sponsored by Lilly Deutschland GmbH and Daiichi Sankyo Deutschland GmbH.

Conflict of interest The authors declare that there is no actual or potential conflicts of interest in relation to this article.

\section{References}

1. Rodriguez I, Kilborn MJ, Liu XK, Pezzullo JC, Woosley RL (2001) Drug-induced QT prolongation in women during the menstrual cycle. JAMA 285(10):1322-1326

2. Seth R, Moss AJ, McNitt S et al (2007) Long QT syndrome and pregnancy. J Am Coll Cardiol 49:1092-1098

3. Rosano GM, Leonardo F, Sarrel PM et al (1996) Cyclical variation in paroxysmal supraventricular tachycardia in women. Lancet 347(9004):786-788

4. Myerburg RJ, Cox MM, Interian A Jr et al (1999) Cycling of inducibility of paroxysmal supraventricular tachycardia in women and its implications for timing of electrophysiologic procedures. Am J Cardiol 83(7):1049-1054

5. Gowda RM, Khan IA, Mehta NJ, Vasavada BC, Sacchia TJ (2003) Cardiac arrhythmias in pregnancy: clinical and therapeutic considerations. Int J Cardiol 88:129-133

6. Stumpf WE, Sar M, Aumuller G (1977) The heart: a target organ for estrogen. Science 196:319-321

7. McGill HC Jr, Anselmo VC, Buchanan JM, Sheridan PJ (1980) The heart is a target organ for androgen. Science 207:775-777

8. Stumpf WE (1990) Steroid hormones and the cardiovascular system: direct actions of estradiol, progesterone, testosterone, glucoand mineralcorticoids, and soltriol (vitamin D) on central nervous regulatory and peripheral tissues. Experientia 46(1):13-25

9. Grohe C, Kahlert S, Lobbert K, Vetter H (1998) Expression of estrogen receptor alpha and beta in rat heart: role of local estrogen synthesis. J Endocrinol 156:R1-R7
10. Nakamura H, Kurokawa J, Bai CX et al (2007) Progesterone regulates cardiac repolarization through a nongenomic pathway: an in vitro patch-clamp and computational modeling study. Circulation 116:2913-2922

11. Nieburgs HW, Kupperman HS, Greenblatt RB (1946) Studies on temperature variations in animals as influenced by the estrus cycle and the steroid hormones. Anat Rec 96(4):529

12. Austin C, Chess-Williams R (1995) The influence of 17-betaoestradiol and the natural oestrous cycle on alpha-adrenoceptormediated responses of the cardiovascular system in the rat. $\mathrm{J}$ Pharm Pharmacol 47(8):656-660

13. Cavalié A, McDonald TF, Pelzer D, Trautwein W (1985) Temperature-induced transitory and steady-state changes in the calcium current of guinea pig ventricular myocytes. Pflugers Arch 405(3):294-296

14. Walsh KB, Begenisich TB, Kass RS (1989) Beta-adrenergic modulation of cardiac ion channels. Differential temperature sensitivity of potassium and calcium currents. J Gen Physiol 93(5):841-854

15. Salata JJ, Jurkiewicz NK, Jow B et al (1996) IK of rabbit ventricle is composed of two currents: evidence for IKs. Am J Physiol Heart Circ Physiol 271:H2477-H2489

16. Varro A, Lathrop DA, Hester SB, Nanasi PP, Papp JG (1993) Ionic currents and action potentials in rabbit, rat, and guinea pig ventricular myocytes. Basic Res Cardiol 88:93-102

17. Liu XK, Katchman A, Drici MD et al (1998) Gender difference in the cycle length-dependent QT and potassium currents in rabbits. J Pharmacol Exp Ther 285(2):672-679

18. Hara M, Danilo P, Rosen MR (1998) Effects of gonadal steroids on ventricular repolarization and on the response to E4031. J Pharmacol Exp Ther 285:1068-1072

19. Roden DM (2008) Clinical practice. Long-QT syndrome. N Engl J Med 358:169-176

20. Lehmann MH, Timothy KW, Frankovich D et al (1997) Age-gender influence on the rate-corrected QT interval and the QT-heart rate relation in families with genotypically characterized long QT syndrome. J Am Coll Cardiol 29:93-99

21. Priori SG, Schwartz PJ, Napolitano C et al (2003) Risk stratification in the long-QT-syndrome. N Engl J Med 348:1866-1874

22. Sauer AJ, Moss AJ, McNitt S et al (2007) Long QT syndrome in adults. J Am Coll Cardiol 49:329-337

23. Migdalovich D, Moss AJ, Lopes CM et al (2011) Mutation and gender-specific risk in type 2 long QT syndrome: implications for risk stratification for life-threatening cardiac events in patients with long QT syndrome. Heart Rhythm 8:1597-1543

24. Locati EH, Zareba W, Moss AJ et al (1998) Age- and sex-related differences in clinical manifestations in patients with congenital long-QT syndrome: findings from the International LQTS Registry. Circulation 97(22):2237-2244

25. Pham TV, Sosunov EA, Gainullin RZ, Danilo PJ, Rosen MR (2001) Impact of sex and gonadal steroids on prolongation of ventricular repolarization and arrhythmias induced by IKr -blocking drugs. Circulation 103:2207-2212

26. Drici MD, Burklow TR, Haridasse V, Glazer RI, Woosley RL (1996) Sex hormones prolong the QT interval and downregulate potassium channel expression in the rabbit heart. Circulation 94(6):1471-1474

27. Cheng J, Su D, Ma X, Li H (2012) Concurrent supplement of estradiol and progesterone reduces the cardiac sensitivity to D, L-sotalol-induced arrhythmias in ovariectomized rabbits. J Cardiovasc Pharmacol Ther 17(2):208-214

28. Pham TV, Sosunov EA, Anyukhovsky EP, Danilo P Jr, Rosen MR (2002) Testosterone diminishes the proarrhythmic effects of dofetilide in normal female rabbits. Circulation 106(16):2132-2136 
29. Brunner M, Peng X, Liu GX et al (2008) Mechanisms of cardiac arrhythmias and sudden death in transgenic rabbits with long QT syndrome. J Clin Invest 118:2246-2259

30. Odening KE, Hyder O, Chaves L et al (2008) Pharmacogenomics of anesthetic drugs in transgenic LQT1 and LQT2 rabbits reveal genotype-specific differential effects on cardiac repolarization. Am J Physiol Heart Circ Physiol 295:H2264-H2272

31. Odening KE, Choi BR, Liu GX et al (2012) Estradiol promotes sudden cardiac death in transgenic long-QT type 2 rabbits while progesterone is protective. Heart Rhythm 9(5):823-832

32. Pham TV, Robinson RB, Danilo P Jr, Rosen MR (2002) Effects of gonadal steroids on gender-related differences in transmural dispersion of L-type calcium current. Cardiovasc Res 53(3):752-762

33. Gaborit N, Varro A, Le Boutier S et al (2010) Gender-related differences in ion-channel and transporter subunit expression in non-diseased human hearts. J Mol Cell Cardiol 49:639-646

34. Kurokawa J, Tamagawa M, Harada N et al (2008) Acute effects of oestradiol on the guinea pig and human $\mathrm{I}_{\mathrm{Kr}}$ channels and drug-induced prolongation of cardiac repolarization. J Physiol 586:2961-2973
35. Ando F, Kuruma A, Kawano S (2011) Synergic effects of $\beta$-estradiol and erythromycin on hERG currents. J Membr Biol 241(1):31-38

36. Kundu P, Ciobotaru A, Foroughi S, Toro L, Stefani E, Eghbali M (2008) Hormonal regulation of cardiac KCNE2 gene expression. Mol Cell Endocrinol 292(1-2):50-62

37. Yang X, Chen G, Papp R, Defranco DB, Zeng F, Salama G (2012) Estrogen upregulates L-type Ca2+ channel via estrogenreceptor- $\alpha$ by a regional genomic mechanism in female rabbit hearts. J Physiol 590(Pt 3):493-508

38. Liu XK, Katchman A, Whitfield BH et al (2003) In vivo androgen treatment shortens the QT interval and increases the densities of inward and delayed rectifier potassium currents in orchiectomized male rabbits. Cardiovasc Res 57(1):28-36

39. Furukawa T, Kurokawa J (2008) Non-genomic regulation of cardiac ion channels by sex hormones. Cardiovasc Hematol Disord Drug Targets 8(4):245-251

40. Chen G, Yang X, Alber S, Shusterman V, Salama G (2011) Regional genomic regulation of cardiac sodium-calcium exchanger by oestrogen. J Physiol 589:1061-1080 